University of Nebraska - Lincoln

DigitalCommons@University of Nebraska - Lincoln

\title{
Moss inhabiting flea beetles (Coleoptera: Chrysomelidae: \\ Galerucinae: Alticini) of the West Indies II: Menudos, a new genus from Puerto Rico and description of methods to collect moss inhabiting flea beetles
}

Adelita Maria Linzmeier

Universidade Federal da Fronteira Sul, Brasil, adelita.linzmeier@uffs.edu.br

Alexander S. Konstantinov

Systematic Entomology Laboratory, USDA, alex.konstantinov@usda.gov

Follow this and additional works at: https://digitalcommons.unl.edu/usdaarsfacpub

Linzmeier, Adelita Maria and Konstantinov, Alexander S., "Moss inhabiting flea beetles (Coleoptera: Chrysomelidae: Galerucinae: Alticini) of the West Indies II: Menudos, a new genus from Puerto Rico and description of methods to collect moss inhabiting flea beetles" (2020). Publications from USDA-ARS / UNL Faculty. 2304.

https://digitalcommons.unl.edu/usdaarsfacpub/2304

This Article is brought to you for free and open access by the U.S. Department of Agriculture: Agricultural Research Service, Lincoln, Nebraska at DigitalCommons@University of Nebraska - Lincoln. It has been accepted for inclusion in Publications from USDA-ARS / UNL Faculty by an authorized administrator of DigitalCommons@University of Nebraska - Lincoln. 


\title{
Article
}

\section{Moss inhabiting flea beetles (Coleoptera: Chrysomelidae: Galerucinae: Alticini) of the West Indies II: Menudos, a new genus from Puerto Rico and description of methods to collect moss inhabiting flea beetles}

\author{
ADELITA M. LINZMEIER ${ }^{1} \&$ ALEXANDER S. KONSTANTINOV ${ }^{2}$ \\ ${ }^{1}$ Universidade Federal da Fronteira Sul, Rua Edmundo Gaievski, 1000, P. O. Box 253, 85.770-000, Realeza, PR, Brazil \\ "'adelita.linzmeier@uffs.edu.br; † https://orcid.org/0000-0002-2979-8728 \\ ${ }^{2}$ Systematic Entomology Laboratory, USDA, c/o Smithsonian Institution, P. O. Box 37012, National Museum of Natural History, Wash- \\ ington, DC 20013-7012,USA. "="alex.konstantinov@usda.gov; 으ttps://orcid.org/0000-0001-6578-6735
}

\begin{abstract}
Menudos Linzmeier \& Konstantinov, a new genus of moss inhabiting flea beetles, containing five species, three of them are new (M. illariosus, M. maricao, and M. toronegro - the type species of the genus), from Puerto Rico is described and illustrated. The new genus is compared to Aedmon Clark, Apleuraltica Bechyne, Andersonaltica Linzmeier \& Konstantinov, Distigmoptera Blake and Ulrica Scherer. Aedmon barberi (Blake, 1943b) and Distigmoptera chamorrae Konstantinov \& Konstantinova, 2011 are transferred to Menudos. A key to Menudos species identification is provided. Methods for collecting moss inhabiting flea beetles and other arthropods are described in detail for the first time.
\end{abstract}

Key words: Distigmoptera, Monoplatina, moss cushions, bryophyte, new species, new genera, collecting methods, Berlese extraction

\section{Introduction}

Moss cushions in the West Indies and in Puerto Rico in particular, continue to reveal previously unknown flea beetles. However, how to classify them is not immediately clear, since bryobiont flea beetles from distant lineages share a number of morphological features: small and oval body, robust appendages and antennae with enlarged apical antennomeres; lack of hind wings and associated reduction of thoracic and elytral structures (Konstantinov et al. 2013). Moss inhabiting Monoplatina share these features with other flea beetles inhabiting moss cushions in the West Indies, e.g. Borinken Konstantinov \& Konstantinova, 2011 and Kiskeya Konstantinov \& Chamorro-Lacayo, 2006. At the same time species within a particular genus are often very similar morphologically (Konstantinov et $a l$. in press) and can only be separated based on seemingly insignificant yet consistent features of their morphology, particularly male and female genitalia.

In this paper we describe three species of bryobiont monoplatine flea beetles and provide new combinations for two previously known ones from Puerto Rico. One of the known species [Menudos chamorrae (Konstantinov \& Konstantinova, 2011)] was originally placed in Distigmoptera Blake, 1943a (type species Distigmoptera apicalis Blake, 1943a by original designation), a genus with 16 known species distributed in North and Central America (Konstantinov et al. 2019). Another species, [Hadropoda barberi (Blake, 1943b)], subsequently considered to be an Aedmon Clark, 1860 as Hadropoda was synonymized with it (Scherer 1962).

As more specimens were collected and otherwise became available for our studies, it became clear that flea beetles from Puerto Rico with some resemblance and previously assigned to Distigmoptera share a number of features and at the same time substantially differ from the type and other continental species of Distigmoptera. Among these distinguishing features are proportions and the shape of the body, pronotum and elytra in particular; coloration of antennae; pronotal and elytral sculpture and setae; and structural differences in the shape of the metatibiae. These features are described below in detail. Based on the aforesaid, we conclude that Aedmon barberi (Figs. 1-6), Distigmoptera chamorrae (Figs. 7-13) and related species (Figs. 14-44) form a distinct genus described below. 


\section{Material and methods}

Beetles were sampled from moss cushions by Berlese extraction. In the field, moss samples were collected from the substrate (trees, ground, and rocks), placed in cloth bags (Fig. 45) (usually locally purchased pillow covers) and brought to the "laboratory". There, moss clusters were placed directly in Berlese funnels (Fig. 48) while keeping quantity of moss limited so that it would dry after about 12 hours inside the funnel. Moss was replaced in each funnel twice a day, in the morning and in the evening. If at the end of a "cycle" moss was still moist, it was kept in the funnel for additional 12 hours. Altogether four funnels were used (Fig. 48) simultaneously through the entire collecting trip (on average eight moss loads per 24 hours). However, by the end of the trip it became clear that there was not enough time to process all the collected moss through Berlese funnels. Therefore, moss samples were sifted into mesh bags, which dramatically reduced the size of the remaining substrate (Fig. 47). At times flea beetles crawled on the sides of the bags and were collected there (Fig. 46). Sifted substrate was then processed through Berlese funnels. It is still unclear if sifting causes a loss of beetle specimens (Konstantinov et al. 2013). Two kinds of Berlese funnel were used; one called "Collapsible Berlese Funnel Trap" produced by Bioquip (Fig. 48, two funnels in the background) and another called "Tray-type Berlese Funnel" by MegaView Science Co., Ltd (Fig. 48, two funnels at the front of the image). Both kinds of funnels were modified in two ways: net filters with mesh opening of 2-4 $\mathrm{mm}$ were put on top of the grill trays to limit amount of debris falling through and instead of vials, whirl packs with labels and alcohol were attached to the apex of the funnel with a duct tape. Content of whirl packs were then gradually unloaded into a sorting tray (Fig. 50) and examined in the laboratory under the microscope (Fig. 49). It is important not to put too much material at once in the tray so that 1 to $2 \mathrm{~mm}$ long beetles and their larvae, which are even smaller, can be seen on the white bottom of the tray. Beetles and other arthropods were then sorted into vials for further processing (Fig. 50).

Dissecting techniques and terminology for most internal and external structures follow Konstantinov (1998). In addition, terminology for adult thoracic structures and ridges follows Lawrence \& Slipinski (2013), Lingafelter \& Konstantinov (2000), and McHugh et al. (1997). Specimen observations were made with a Zeiss Stemi SV11 Apo microscope. Digital photographs of morphological structures were taken with Axio Zoom V16 microscope and AxioCam HRC digital camera attached to it and with AxioCam HRC Zeiss attached to Leitz Diaplan compound microscope. Additional images were taken with Macropod Pro photomacrography system (Macroscopic Solutions, LLC, Tolland CT). Map was created by entering way points of collecting events in questions into Google Earth Pro. Screen shot of resulted map was then edited in Adobe Photoshop for consistency with other images used in this paper. The beetles are deposited in the collection of the National Museum of Natural History, Smithsonian Institution, Washington, D.C. (USNM).

\section{Results}

\section{Menudos Linzmeier \& Konstantinov new genus}

(Figs. 1-44)

Description. Body $1.76-2.33 \mathrm{~mm}$ long and $0.94-1.32 \mathrm{~mm}$ wide, elliptic, pilose, shiny, slightly convex in lateral view. Color brown, blackish or yellowish with golden and black setae forming different patterns.

Head hypognathous, slightly convex in lateral view. Vertex densely covered with large setiferous pores. Supraorbital pore indistinguishable to distinct. Antennal calli rounded, punctured or smooth, slightly raised above surface of vertex, separated by relatively wide and deep midfrontal sulcus. Supracallinal, supraorbital and suprafrontal sulci absent, however there are shallow impressions in their places. Orbital sulcus absent. Orbit narrow, narrower than diameter of antennal socket. Interantennal space wide, as wide as the length of first antennomere. Antennal socket small, rounded. Frontal ridge between antennal sockets wide and flat or slightly raised forming a single triangular structure with anterofrontal ridge, generally punctuated. Eye small, rounded, slightly projected. Labrum notched in middle, with six setiferous pores, four with long setae and two with short setae. First maxillary palpomere conical, slightly longer than wide, wider at apex; second maxillary palpomere wider and slightly shorter than first, wider at apex; third palpomere thinnest, conical, short, slightly shorter than second. First and second labial palpomeres wider than long; third conical. Antenna with 11 antennomeres, pubescent; antennomeres 7 to 11 widest, 7 to 10 almost rounded to longer than wide; antennomere 4 shortest. 
Pronotum rectangular, wider than long, not margined laterally. Anterior margin straight, posterior margin concave, sides parallel, slightly rounded posteriorly. Anterior and posterior setiferous pores present, facing dorsolaterally. Surface densely punctuated with closely placed punctures, pilose. Pronotal surface uneven, raised with two longitudinal ridges anteromedially, separated by two wide concavities between them, the most posterior concavity usually shallower, placed near base. Scutellum triangular, densely covered with yellow or white setae directed posteriorly and ventrally on sides. Some shorter dark setae along pronotal margin bent dorsally like hooks.

Elytra elliptical, apical third bent (in lateral view). Elytral surface uneven, shiny, deeply punctured, with dense black and golden yelow, recumbent setae. Few similarly colored long, semi-erect setae situated throughout surface. Punctures forming nine striae (not counting short scutellar and marginal striae). Scutellar striae short. Interspaces convex or flat, with interspaces between puncture rows two and three at basal third always convex. Basal calli poorly developed. Humeral calli absent. Small depression posterior to basal callus more or less evident. Epipleura narrow, sinuous, oblique, visible in lateral view, narrowing at elytral apex, more or less reaching elytral apex. Elytral apex slightly truncate. Hind wings absent.

Prosternal intercoxal process canaliculate, covered with deep, often merging, punctures, extended and widened posteriorly beyond coxa. Posterior end about twice as wide as middle. Procoxa elongate. Procoxal cavities closed posteriorly. Mesosternum shorter than prosternum, punctuated, mesosternal intercoxal process concave with lobes raised above metasternum. Metasternum short, smooth to punctuated, with sparse pilosity, concave medially, as long as prosternum; anterior margin deeply punctured, margined; anterior process narrowly rounded; posteriorly margined with an inverted U-shaped depression medially. Metanotum greatly simplified. Among various ridges only two bordering scutellar groove present. Prephragma and metapostnotal mediophragmite absent. Metendosternite simplified as well, its stem short, arms slender, all missing sclerotized ridges.

Pro- and mesofemora slightly dilated medially; tibiae subcylindrical, obliquely narrowed at apex (in lateral view), pubescence sparsely distributed. First to third pro- and mesotarsomeres small; first slightly longer than wide; second slightly wider than long; third slightly wider than second, bilobed; fourth tarsomere as long as first and second together, the thinnest. Metafemur greatly enlarged, about 1.6 times longer than wide, longer than metatibia, sparsely pilose, with denser pilosity dorsally. Metatibia nearly straight; wider at apex in lateral view, slightly curved in dorsal view. Apex of outer lateral dorsal ridge with seven denticles. Inner lateral dorsal ridge with five denticles at apex. Metatibial spur short. Outer and inner dorsal margins of metatibia not connected at apex. Metatarsomeres inserted preapically; tarsomeres one and two similar in size, longer than wide; third half as long as second, not bilobed; fourth globose. Claws bifid (appendiculate in females).

Abdomen sparsely pubescent, with five visible ventrites, each convex in lateral view. Anterior projection of ventrite 1 deeply punctuated. Ventrite 5 with distinct sexual dimorphism: males with concavity medially on posterior margin; females without this concavity, posterior margin slightly rounded. Pygidium exposed.

Median lobe simple, flattened dorso-ventrally, slightly curved in lateral view, with apex bent ventrally in lateral view; lateral margins parallel in ventral view, narrowing towards apex; apex subtriangular without denticle. In female posterior part of sternite eight lightly sclerotized along its entire margin. Tignum with rounded anterior margin wider than middle part; posteriorly more sclerotized in middle, but more or less evenly otherwise, bearing moderately long setae. Vaginal palpi elongate, anteriorly and along middle strongly sclerotized and merged anteriorly for one third of their length, each with about eight setae at apex, with posterior sclerotization relatively long. Spermatheca curved, with receptacle and pump not differentiated from each other (pump about as wide as receptacle). Apex of pump with flattened projection. Spermathecal duct long, forming "S" coils.

Sexual dimorphism. Apart from the tip of the abdomen being obviously different in both sexes, males of flea beetles often have wider pro- and mesotarsomeres. In this genus, males are a bit darker in color, body surface in females is usually dark brown to amber; number of white antennomeres in males and females is different depending on the species; and even less common in flea beetles females have wider head and frontal ridge compared to males (Fig. 3 and 5).

Etymology. The name of the genus alludes to Menudos-Puerto Rican-based boy band, that achieved much success during the 1980s. Besides this, the word "Menudos" means "small" a characteristic observed in the species (less than $3 \mathrm{~mm}$ long).

Type species. Menudos toronegro Linzmeier \& Konstantinov, new species.

Remarks. We compared Menudos with the following West Indian Monoplatina genera: Aedmon Clark, 1860, Apleuraltica Bechyné, 1956, Distigmoptera Blake, 1943 and Ulrica Scherer, 1962. In addition, we compared it to 
Andersonaltica Linzmeier \& Konstantinov, 2012, which representatives inhabit leaf litter in Central America. Distigmoptera is included here as some West Indian Monoplatina were identified as such.

Menudos shares the following characters with the rest of West Indian Monoplatina and Andersonaltica: closed procoxal cavities; puctured-striated and pilose elytra; head and pronotum covered with large punctures; pronotum with tubercles, frontal ridge between antennal sockets wide and last five antennomeres much wider than basal. Menudos can be differentiated from these genera by the interspaces between puncture rows two and three convex basally, antennomere 4 shortest and exposed pygidium.

In addition to the above mentioned characters, Menudos can be differentiated from Distigmoptera (characters in parenthesis) by the following: oval body shape in dorsal view, elytra convex in lateral view (more or less parallel sided in dorsal view, flat in lateral view); pronotum about 1.4 times wider than long, (pronotum generally more elongate, about 1.1 times wider than long); pronotal protuberances more developed (pronotal protuberances more or less flat); humeral callus absent (humeral callus prominent); setae on pronotum and elytra not erect (setae in part erect). Blake (1943a) specifically mentioned that in Distigmoptera there is "a depression running obliquely from within the humerus to a more or less pronounced depressed spot on each elytron near the suture before the middle" present in all the species, especially in ones with more southern distribution. Blake used this characteristic for the name of the genus. This feature is missing in most Menudos species. Only in M. toronegro barely perceptible depression can be seen, but it does not run from the humerus as occurs in all Distigmoptera species. Also, in Menudos, the metatibia is without a transverse ridge above insertion of tarsus. In Distigmoptera, the apex of the inner and outer dorsal ridge of metatibia come together forming a transverse ridge above insertion of tarsus, that in lateral view forms a preapical dorsal projection. This feature is absent in Menudos.

Menudos differs immediately from Ulrica, which in having glabrous head, pronotum, and elytra; antennae with distal antennomeres not much wider than basal; relatively small punctures on the dorsal surface of the body; smooth dorsal surface and flat elytral interspaces; and long metatarsal spur (Konstantinov \& Konstantinova 2011).

Menudos and Apleuraltica both lacking humeral calli, have uneven elytra with interspaces between puncture rows convex, and rounded antennal calli, separated by a deep midfrontal sulcus. They can be differentiated (characters for Apleuraltica in parenthesis) by the presence of at least one antennomere distinctly lighter in color (antennomere unicolored); antennomeres 8 to 10 almost rounded to longer than wide (antennomeres 8 to 10 wider than long); pronotum with two ridges anteromedially (pronotum with three ridges, two anteromedially and one posteromedially); basal calli poorly developed (basal calli well developed); if present at all, only a small depression posterior to basal callus more or less evident (well-developed impression posterior to basal callus); metatibia without transverse ridge above insertion of tarsus (metatibia with transverse ridge above insertion of tarsus forming a preapical dorsal projection, in lateral view). This last character in Apleuraltica was misinterpreted in Konstantinov \& Konstantinova (2011).

From Andersonaltica (characters in parenthesis), Menudos can be easily differentiated by the elyptic and slightly convex body (rounded, highly convex in lateral view), shorter setae covering the body (longer setae covering the body), basal calli poorly developed (basal calli generally well developed), antennal calli separated by a deep midfrontal sulcus (antennal calli widely separated anteriorly) and antennomeres 7 to 10 almost rounded to longer than wide (antennomeres 7 to 10 forming tight club).

Menudos can be separated from Aedmon based on the following features: shape of the pronotum and elytra (sides more convex in Menudos); midfrontal sulcus relatively wide and deep (narrow in Aedmon); metatibia with a number of short, stocky denticles preapically (such denticles absent in Aedmon), lacking preapical tooth laterally (tooth followed by excavation in Aedmon).

\section{Menudos barberi (Blake, 1943b) nov. comb.}

(Figs. 1-6)

barberi Blake, 1943b: 440 (type locality: Gov. Finca, Villalba, Puerto Rico; holotype, male, USNM); as Hadropoda. Scherer, 1962: 512; as Aedmon.

Redescription. Body length 1.79-1.96 mm, width 0.94-1.15 mm. Head, except mouthparts, antenna, except antennomere 5 and 6 in males and 5 in females, pronotum, base of elytron, and metafemur dark brown to blackish. 


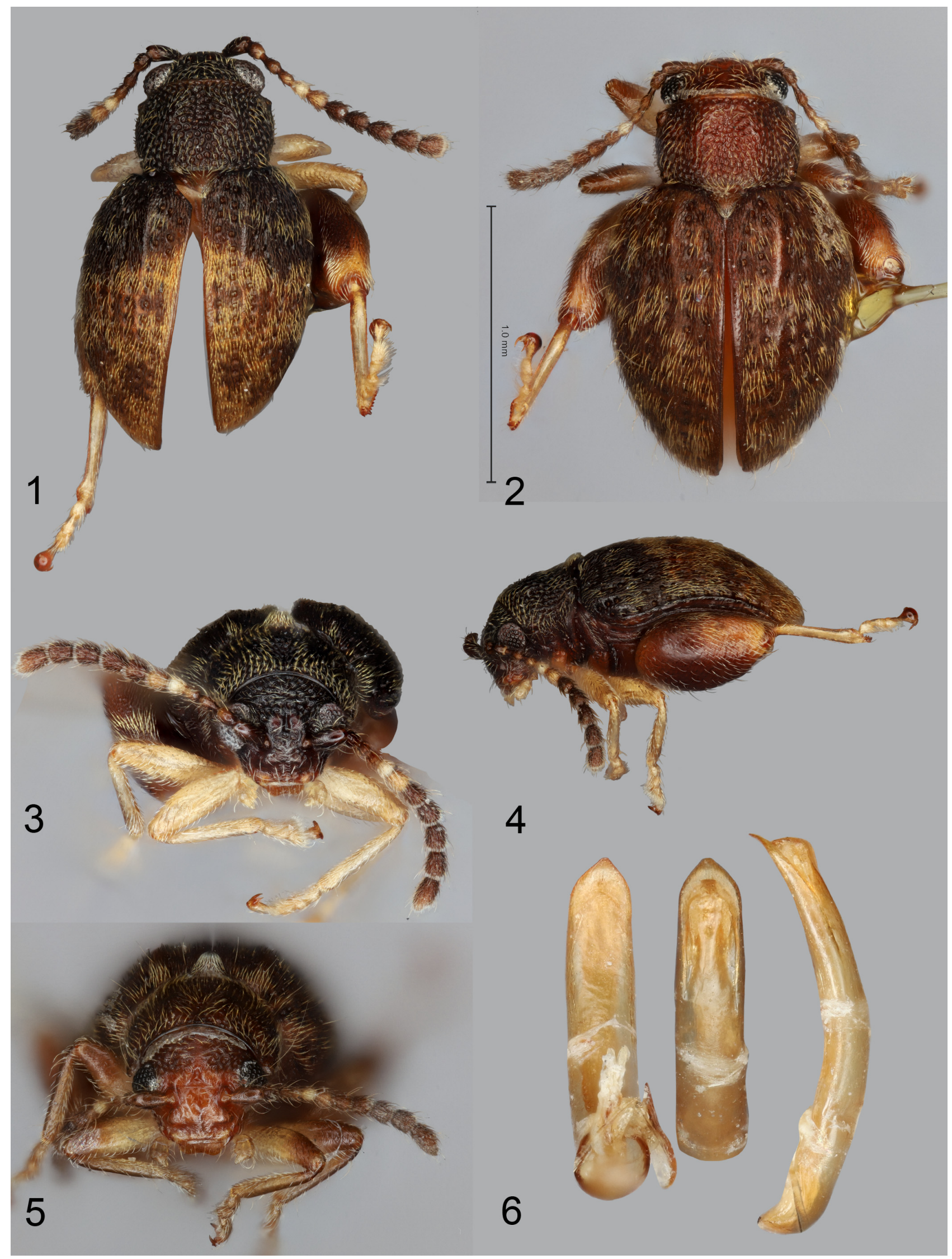

FIGURES 1-6. Menudos barberi (Blake). 1, habitus, holotype, male, dorsal view. 2, habitus, paratype, female, dorsal view. 3 , frontal view, holotype, male. 4 , habitus, holotype, male, lateral view. 5, frontal view, paratype, female. 6 , median lobe of aedeagus, holotype (ventral, dorsal, and lateral views). 
In male scutellum and apical part of elytra yellowish. Venter dark brown, except yellowish last ventrite. Antennomeres 1 and 2 dark. In males antennomeres 5 and 6 white. In females antennomere 5 white. Sparse golden yellow setae scattered evenly across pronotum. Golden yellow setae form distinct pattern on elytra with wide band in the posterior half of elytra having dark spot near suture. Elytral apex with light setae. In addition, thin band of white setae situated at base of elytra. Some thinner and darker setae also present. Hind femora with light and dark setae forming a pattern in which dark setae make a spot on top of femur. Supraorbital pore distinct among other setiferous pores on vertex. Antennal calli slightly raised above surrounding surfaces, smooth. Supracallinal sulcus absent, however there is a shallow impression in its place. Similar impression in place of suprafrontal sulcus. Midfrontal sulcus wider basally than towards top of antennal calli, more so in female. Frontal and anterofrontal ridges slightly raised, with uneven surface. Anterofrontal ridge in middle abruptly extends towards labrum. Proportions of antennomere lengths in male: 12:6:8:7:7:7:7:9:9:9:11; in female: 12:7:9:6:7:7:8:7:8:9:12. Pronotum rectangular, 1.5 times wider than long. Punctures as dense on pronotal protuberances as between them. Scutellum covered with setae denser than elytra. Scutellar row of punctures very short, consisting of one or two punctures. Interspaces convex, less so in between puncture rows three and four. Proportions of mesotarsomere length in male as follows: 10:8:11:22. Median lobe simple, slightly and evenly curved in lateral view; in ventral view, with lateral sides almost parallel, apex subtriangular, without denticle. Venter apically flatter than basally. Dorsal flap comes close to apex.

Remarks. Menudos barberi can be differentiated from M. chamorrae by the presence of the stripe of yellowish setae at the base of elytra (stripe is absent in M. chamorrae); unicolorous female elytra (it is dark at the base and yellowish at the apex in M. chamorrae); midfornal sulcus being wider at the base than deeper between antennal calli (it is parallel sided in M. chamorrae); median lobe of the aedeagus evenly convex in lateral view with the dorsal flap coming close to the tip of the median lobe (in M. chamorrae, this flap comes at a distance to the tip of the lobe).

Habitat. Habitat of M. barberi is not known. Blake (1943b) mentioned the third specimen collected by Oakley at the Principi Finca, Adjuntas on Areca catech $u$ L. (Arecaceae). However, this specimen could not be located in the USNM collection, hence we are unable to confirm its conspecificity.

Type material. Holotype, male, with labels as follows: 1) Host unknown, Ins. Gov. Finca, Villalba, Puerto Rico, coll. 18 June, 34. R. G. Oakley; 2) sl \#5658; 3) Type No 5616, USNM; 4) Hadropoda barberi Blake type (USNM). Paratype female, with the same label and on the same pin as holotype (USNM).

\section{Menudos chamorrae (Konstantinov \& Konstantinova, 2011) nov. comb.}

(Figs. 7-13)

chamorrae Konstantinov and Konstantinova, 2011: 71 (type locality: Puerto Rico: Toro Negro; holotype, male USNM), as Distigmoptera.

Redescription. Body length 1.72-2.27 mm, width 0.91-1.14 mm. Head, except mouthparts, antenna, except antennomere five in males and five and six in females, pronotum, base of elytron, and metafemur dark brown to blackish. In female scutellum and apical part of elytra yellowish. Venter dark brown, except yellowish last ventrite. Antennomeres 1 and 2 dark. In males antennomere 5 white. In females antennomeres 5 and 6 white. Sparse golden yellow setae positioned laterally at base of pronotum. Golden yellow pubescence forms distinct pattern on elytra with wide band in the posterior half of elytra having dark spot near suture. Elytral apex with light setae. Some thinner and darker setae also present. Hind femora with light and dark setae forming a pattern in which dark setae make transverse band across top of femur. Supraorbital pore distinct among other setiferous pores on vertex. Antennal calli slightly raised above surrounding surfaces, smooth. Supracallinal sulcus absent, however there is a shallow impression in its place. Similar impression in place of suprafrontal sulcus. Midfrontal sulcus parallel sided. Frontal and anterofrontal ridges slightly raised, smooth. Anterofrontal ridge in middle abruptly extends towards labrum. Proportions of antennomere lengths in male: 12:4:6:5:5:5:7:7:7:6:9; in female: 12:6:5:5:5:6:6:6:6:7:9. Pronotum rectangular, 1.47 wider than long. Punctures as dense on pronotal protuberances as between them. Scutellum covered with setae denser than those on elytra. Scutellar row of punctures very short, consisting of one or two punctures. Elytral punctures on rows 2 and 3 placed close to each other. Interspaces convex, less so in between puncture rows 3 and 4. Proportions of mesotarsomere length in male as follows: 10:8:9:22. Median lobe simple, slightly curved in lateral view with more abrupt curvature near middle; in ventral view, with lateral sides almost parallel, apex subtriangular without denticle. Venter apically flatter than basally. In female genitalia, posterior part of sternite eight sclerotized along its entire 


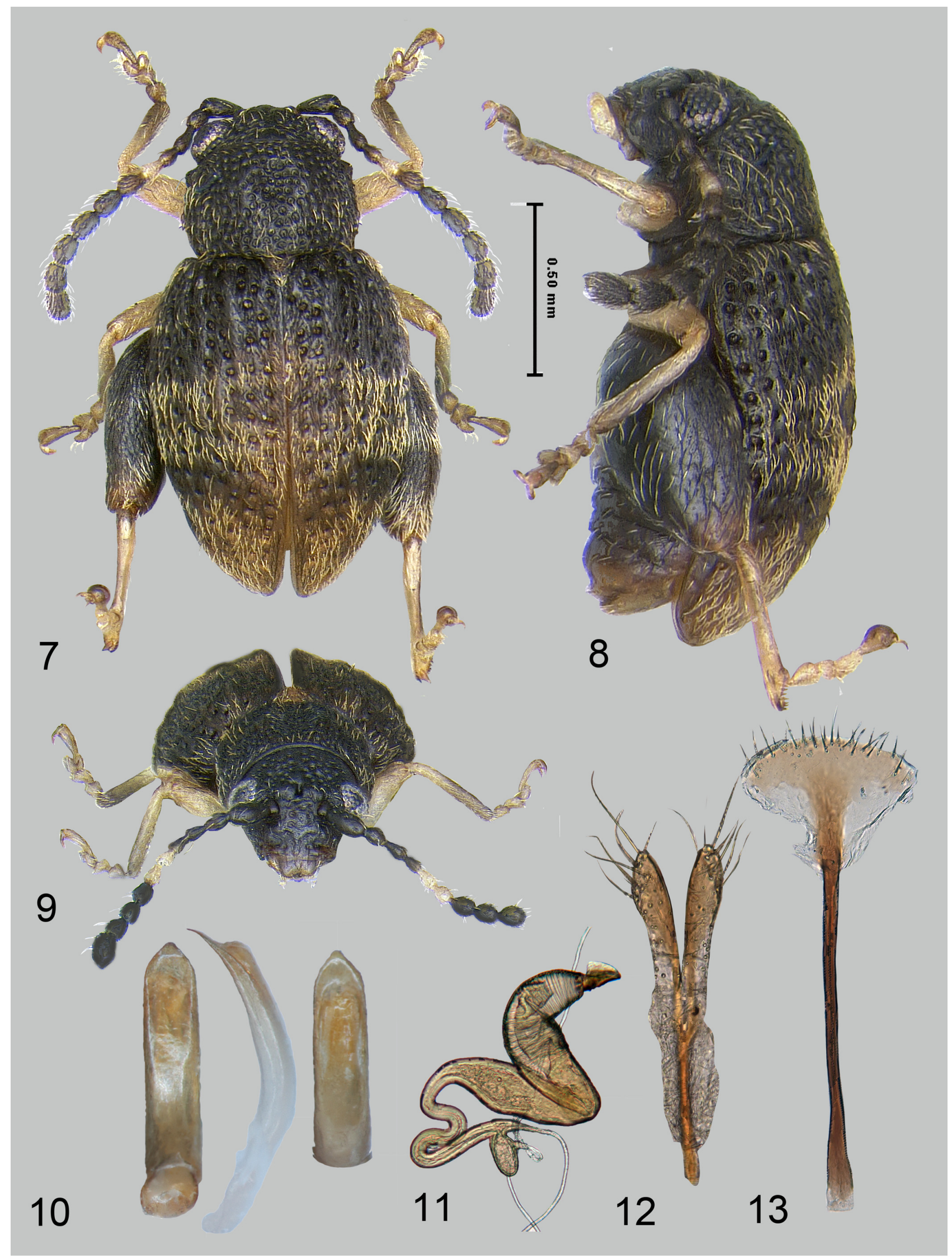

FIGURES 7-13. Menudos chamorrae (Konstantinov \& Konstantinova). 7, habitus, male, dorsal view. 8, habitus, lateral view. 9, frontal view, female. 10, median lobe of aedeagus, holotype (ventral, lateral, and dorsal views). 11, spermatheca. 12, vaginal palpi. 13, tignum. 
margin. Tignum with rounded posterior margin, widely sclerotized along entire posterior margin, bearing many moderately long setae. Vaginal palpi elongate, anteriorly and along middle strongly sclerotized and merged anteriorly for more than half of their length, each with about eight setae at apex, with posterior sclerotization shorter than anterior. Spermatheca curved, with receptacle and pump not differentiated from each other (pump about as wide as receptacle). Apex of pump with flattened projection. Spermathecal duct long, forming "S" coils.

Remarks. Menudos chamorrae can be differentiated from M. barberi by the absence of stripe of yellowish setae at the base of elytron (stripe of yellowish hair present at the base of elytra in M. barberi); yellow color of the posterior half of the elytron in females (elytron is unicolorous in female of M. barberi); in males the posterior half of the elytron is light in color in M. barberi, while it is dark in M. chamorrae; parallel sided midfrontal sulcus (midfrontal sulcus is wider at the base then deeper between antennal calli in M. barberi); median lobe of the aedeagus more abruptly curved at base in lateral view with the dorsal flap coming at a distance to the tip of the lobe (in $M$. barberi median lobe slightly and evenly curved in lateral view and dorsal flap comes close to the tip of the median lobe).

Habitat. Menudos chamorrae was collected by sweeping at the mid elevation forest road on Toro Negro. It is unknown if it is associated with moss cushions or not. Tree trunks on the side of the road where the specimens were collected had some moss cover.

Type material. Holotype, male, with labels as follows: 1) Puerto Rico: Toro Negro, $18^{\circ} 11.850^{\prime} \mathrm{N}, 66^{\circ} 29.533^{\prime} \mathrm{W}$, 904 m, 20.VI.2008, leg. M. L. Chamorro (USNM). Paratype female, with the same label as holotype (USNM).

\section{Menudos illariosus Linzmeier \& Konstantinov, new species}

(Figs. 14-21)

Description. Body length $2.02 \mathrm{~mm}$, width $1.15 \mathrm{~mm}$. Head and pronotum pale brown. Elytra brown to slightly lighter toward apex. Antennae brown, except antennomeres 1 and 2 dark brown and 5 much lighter. Venter dark brown, except last ventrite. Legs and last ventrite as brown as elytra. Pronotal and elytral pubescence golden yellow without distinct pattern. Golden yellow setae occupy most of pronotum. Some thinner and darker setae also present. Hind femora with light and dark setae forming a pattern in which dark setae make a strip along front margin of femur. Supraorbital pore indistinct among other setiferous pores on vertex. Antennal calli slightly raised above surrounding surfaces, smooth. Supracallinal sulcus absent, however there is a shallow impression in its place. Similar impression in place of suprafrontal sulcus. Frontal and anterofrontal ridges slightly raised, smooth. Anterofrontal ridge in middle abruptly extends towards labrum. Proportions of antennomere lengths in female: 14:10:10:8:9:8:8: 9:10:11:15. Pronotum rectangular, 1.4 times wider than long. Punctures as dense on pronotal protuberances as between them. Scutellum covered with setae denser than those on elytra. Elytral punctures on row 2 and 3 placed close to each other but with a break near middle. Interspaces convex, less so in between puncture rows 3 and 4 . Epipleura nearly reaching elytral apex. Ventral thoracic surface covered with coarse punctures. Proportions of mesotarsomeres 10:8:9:24. Tignum posteriorly widely sclerotized mostly in middle, rest of the sclerites membranous, evenly sclerotized, bearing some moderately long setae. Vaginal palpi anteriorly fused and strongly sclerotized. Spermatheca curved more or less in one plane, with receptacle and pump not differentiated from each other (pump about as wide as receptacle). Receptacle gradually morphs into duct. Apex of pump with flattened projection. Spermathecal duct long, forming single coil.

Remarks. Menudos illariosus can be differentiated from other species of Menudos by the brownish color of the body, the color is slightly darker at the base of elytra and lighter at the apex; antennomere 5 slightly lighter in color; antennal calli, frontal and anterofrontal ridges smooth, lacking punctures; frontal ridge wide; hind femur with light and dark setae forming a pattern in which dark setae make a strip along frontal margin of femur; golden yellow setae occupy most of pronotum; pubescence on elytra without distinct pattern; spermathecal duct long, forming single coil. Vaginal palpi were damaged during dissection, so their posterior part is missing.

Habitat. Menudos illariosus was collected at the highest point of Puerto Rico, near phone towers on Toro Negro. Moss bearing trees are located on the side of the road that leads to the towers (Figs. 54-55).

Etymology. This species is named after Dr. Illarion Turko (Germantown, MD), in recognition of his participation in a beetle collecting trip in Puerto Rico in September 2014. 


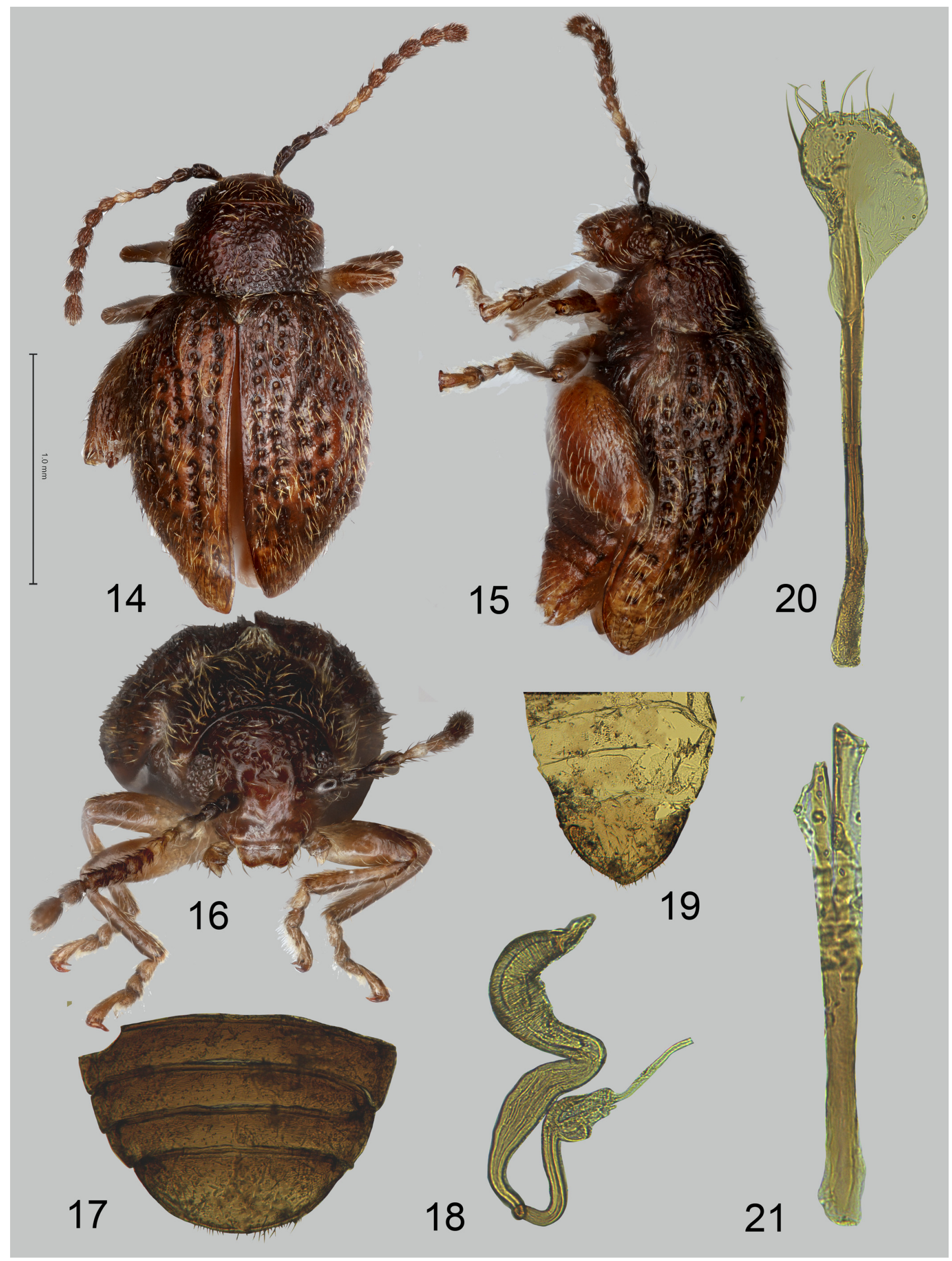

FIGURES 14-21. Menudos illariosus Linzmeier \& Konstantinov, new species. 14, habitus, holotype, female, dorsal view. 15, habitus, holotype, female, lateral view. 16, frontal view, holotype, female. 17, last four abdominal ventrites. 18, spermatheca. 19 , last abdominal tergite. 20, tignum. 21, vaginal palpi. 
Type material. Holotype, female, with labels as follows: 1) Puerto Rico: Toro Negro, 3.IX.2014/ N18.10.335 W66.35.504/ h-1350m, moss, WP-478/ leg. A. Konstantinov; 2) Holotype Menudos illariosus new species des. A.M. Linzmeier \& A. Konstantinov, 2020 (USNM).

\section{Menudos maricao Linzmeier \& Konstantinov, new species}

(Figs. 22-26)

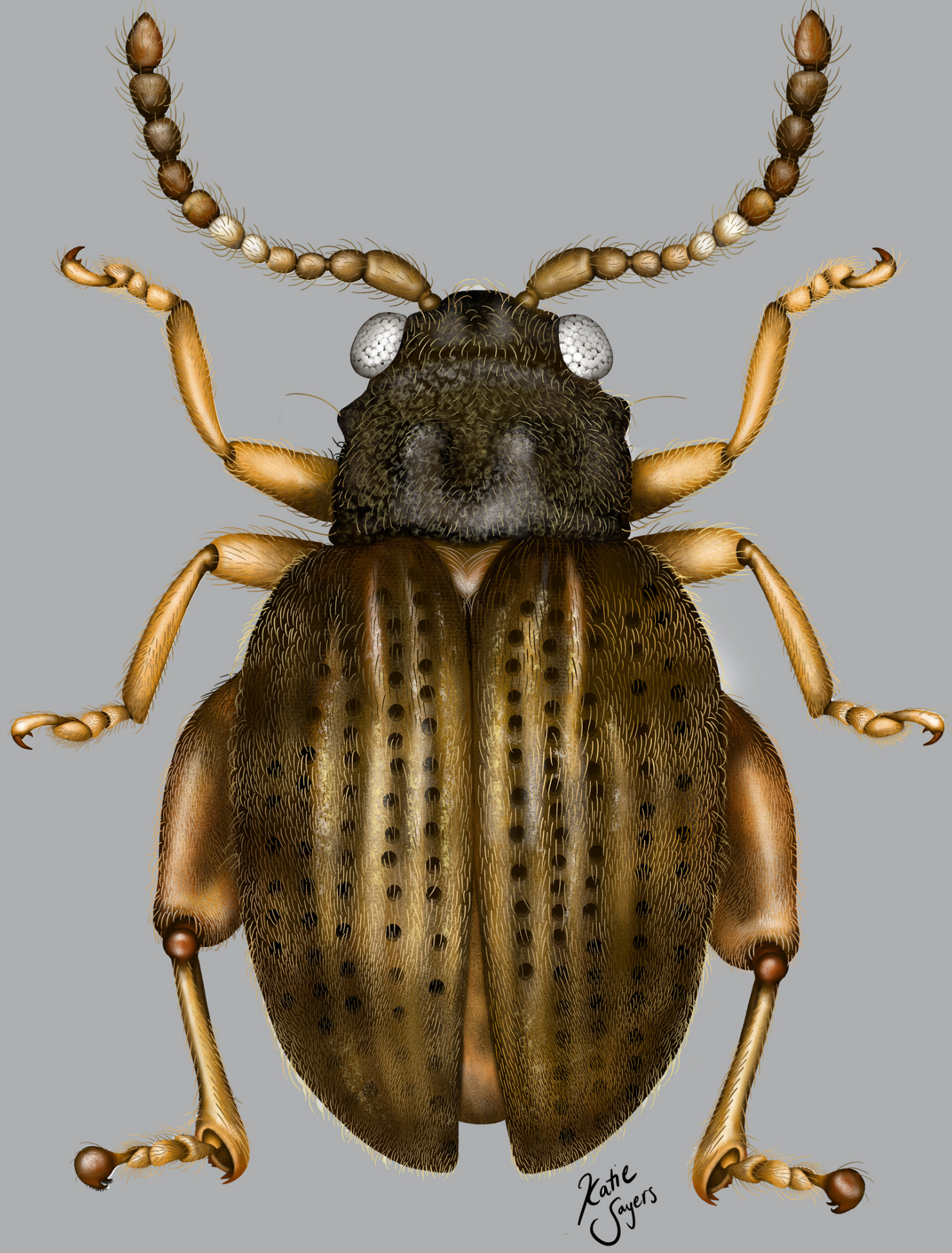

FIGURE 22. Menudos maricao Linzmeier \& Konstantinov, new species. (illustration by Katie Sayers). 


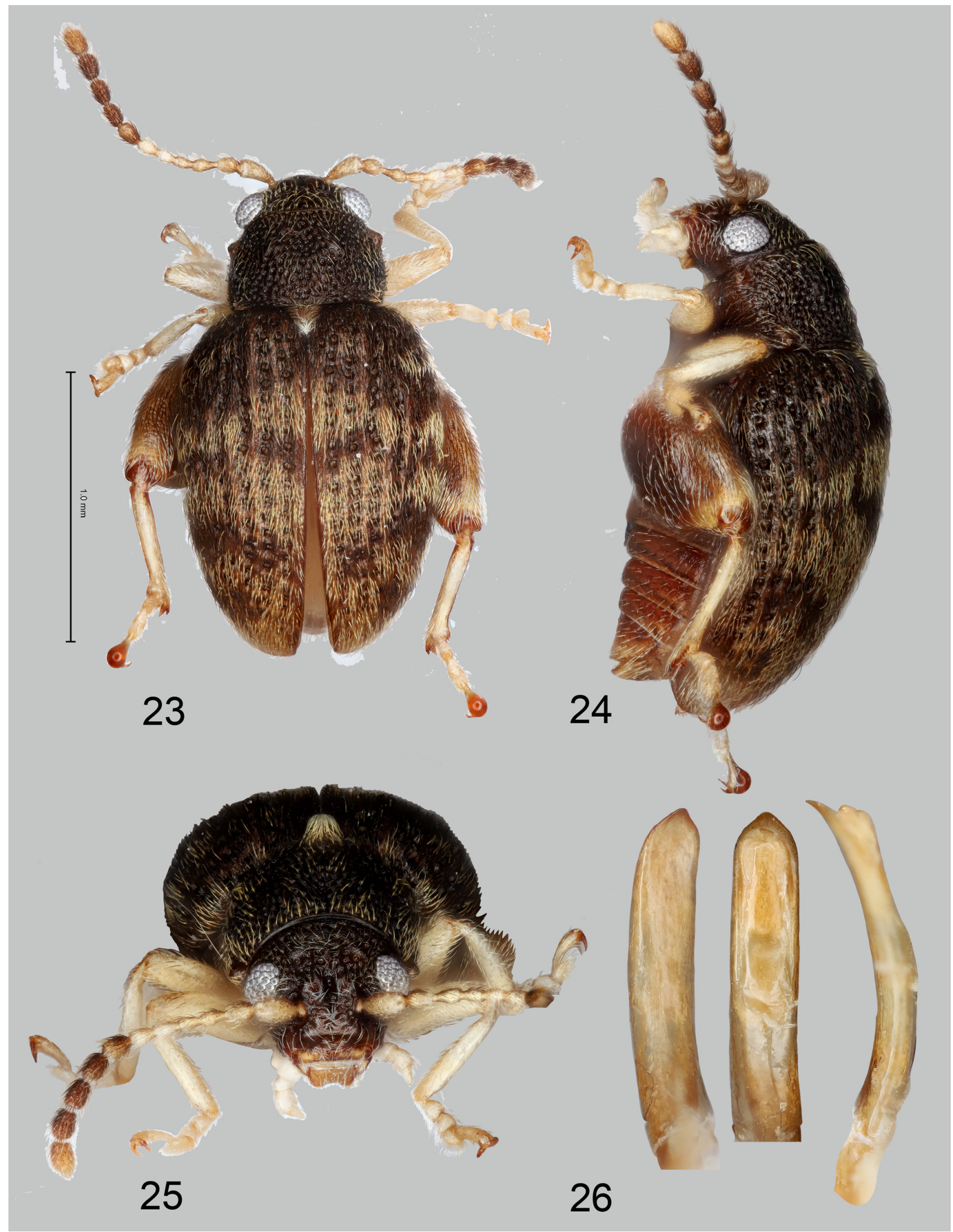

FIGURES 23-26. Menudos maricao Linzmeier \& Konstantinov, new species. 23, habitus, male, dorsal view, holotype. 24, habitus, female, lateral view, paratype. 25, frontal view, male, holotype. 26, median lobe of aedeagus, holotype (ventral, dorsal, and lateral views). 
Description. Body length 1.76-2.10 mm, width 0.94-1.15 mm. Head and pronotum blackish. Elytra lighter than pronotum, even lighter toward apex. Front and middle legs, and hind tibiae whitish. Antennomeres 1 to 6 and tip of antennomere 11 whitish. Antennomeres 7-10 brown. Venter dark brown, except last visible abdominal segment lighter. Pronotal pubescence yellowish laterally, darker in middle. Scutellum densely covered with whitish-goldish setae. Golden yellow elytral pubescence arranged with four more or less straight transverse bands (first — basal, band the narrowest, does not reach suture). Fourth band connect to golden yellow pubescence of elytral apex with wide longitudinal band along suture. In males, bands narrower than in females. Hind femur with light and dark setae forming a pattern in which light setae form two perpendicular strips in middle and apex of femur. Supraorbital pore distinct among other setiferous pores on vertex. Antennal calli slightly raised above surrounding surfaces, smooth. Supracallinal sulcus absent, however there is a very shallow impression in its place. Similar impression in place of suprafrontal sulcus. Frontal and anterofrontal ridges slightly raised, smooth. Extension of anterofrontal ridge towards labrum indistinct. Proportions of antennomere lengths in male: 16:8:8:7:8:8:8:9:9:10:10. Pronotum rectangular, 1.4 wider than long. Punctures as dense on pronotal protuberances as between them. Elytral interspaces convex, less so in between puncture rows 3 and 4. Elytral punctures on row 2 and 3 placed at distance from each other consistently throughout entire length of rows. Epipleura nearly reaching elytral apex. Ventral thoracic surface covered with coarse punctures. Proportions of mesotarsomeres 7:5:6:14. Median lobe of aedeagus simple, dorsoventrally flattened; ventrally with slight longitudinal impression near apex, parallel lateral margins converging abruptly towards apex; in lateral view slightly and evenly curved with apex abruptly curved ventrally.

Diagnosis. Menudos maricao can be easily differentiated from other species of Menudos by the antennomeres 1 to 5 lighter in color, unique pattern of light and dark setae on pronotum, elytra and hind femur. Menudos maricao is very similar to M. chamorrae in color pattern but can be differentiated by the color of antennomeres [in M. chamorrae antennomere 5 (male), and 5 and 6 (female) lighter in color].

Habitat. Menudos maricao was collected below the highest point of Maricao mountains, near the phone towers. Moss was growing on the vertical wall on the side of the road that leads to the towers (Figs. 52-53).

Etymology. The specific epithet is a noun in apposition based on the type locality.

Type material. Holotype, male, with labels as follows: 1) Puerto Rico: Maricao, 6.IX.2014/ N18.08.89 W66.58.932/ h-902m, moss, WP-486/ leg. A. Konstantinov; 2) Holotype Menudos maricao des. A. M. Linzmeier \& A. Konstantinov, 2020 (USNM). Paratypes, with the same labels as holotype, 1 male, 1 female (USNM).

\section{Menudos toronegro Linzmeier \& Konstantinov, new species}

(Figs. 27-44)

Description. Body length 1.89-2.33 mm, width $1.05-1.32 \mathrm{~mm}$. Head and pronotum blackish. Elytra at base as dark as pronotum, lighter toward apex, apex orange. Front and middle legs, and hind tibiae whitish. Antennomeres 1 and 2, 5 and 6, and 10 and 11 whitish. Antennomeres 3 and 4, 7-9 brown. Venter dark brown, except last visible segment lighter. Pronotal pubescence yellowish laterally, darker in middle. Scutellum densely covered with silvery setae. Golden yellow elytral pubescence arranged with five abruptly bent transverse bands (first - basal, band reaches suture). Fifth band connect to golden yellow pubescence of elytral apex with wide longitudinal band along suture. In males bands narrower than in females. Hind femur with light and dark setae forming a pattern in which light setae make two wide perpendicular strips in middle and apex of femur. Supraorbital pore indistinct among other setiferous pores on vertex. Antennal calli slightly raised above surrounding surfaces, with few punctures. Supracallinal sulcus absent, however, there is a very shallow impression in its place. Similar impression in place of suprafrontal sulcus. Frontal and anterofrontal ridges slightly raised, with punctures. Extension of anterofrontal ridge towards labrum indistinct. Proportions of antennomere lengths in male: 15:7:10:7:7:7:9:8:9:10:11. Pronotum rectangular, 1.4 times wider than long. Punctures sparser on pronotal protuberances as between them. Elytral interspaces moderately convex, less so in between puncture rows 3 and 4. Elytral punctures on row 2 placed at distance from each other consistently throughout entire length of row. Punctures in rows 3 and 4 slightly confused. Epipleura nearly reaching elytral apex. Ventral thoracic surface covered with coarse punctures. Proportions of mesotarsomeres 8:5:9:14. Median lobe of aedeagus simple, dorsoventrally flattened; ventrally with slight longitudinal impression near apex, slightly curved sides, converging gradually towards apex; in ventral view apex forms barely distinct denticle, in lateral view slightly curved more so below middle with apex abruptly curved ventrally. Spermatheca abruptly curved, 


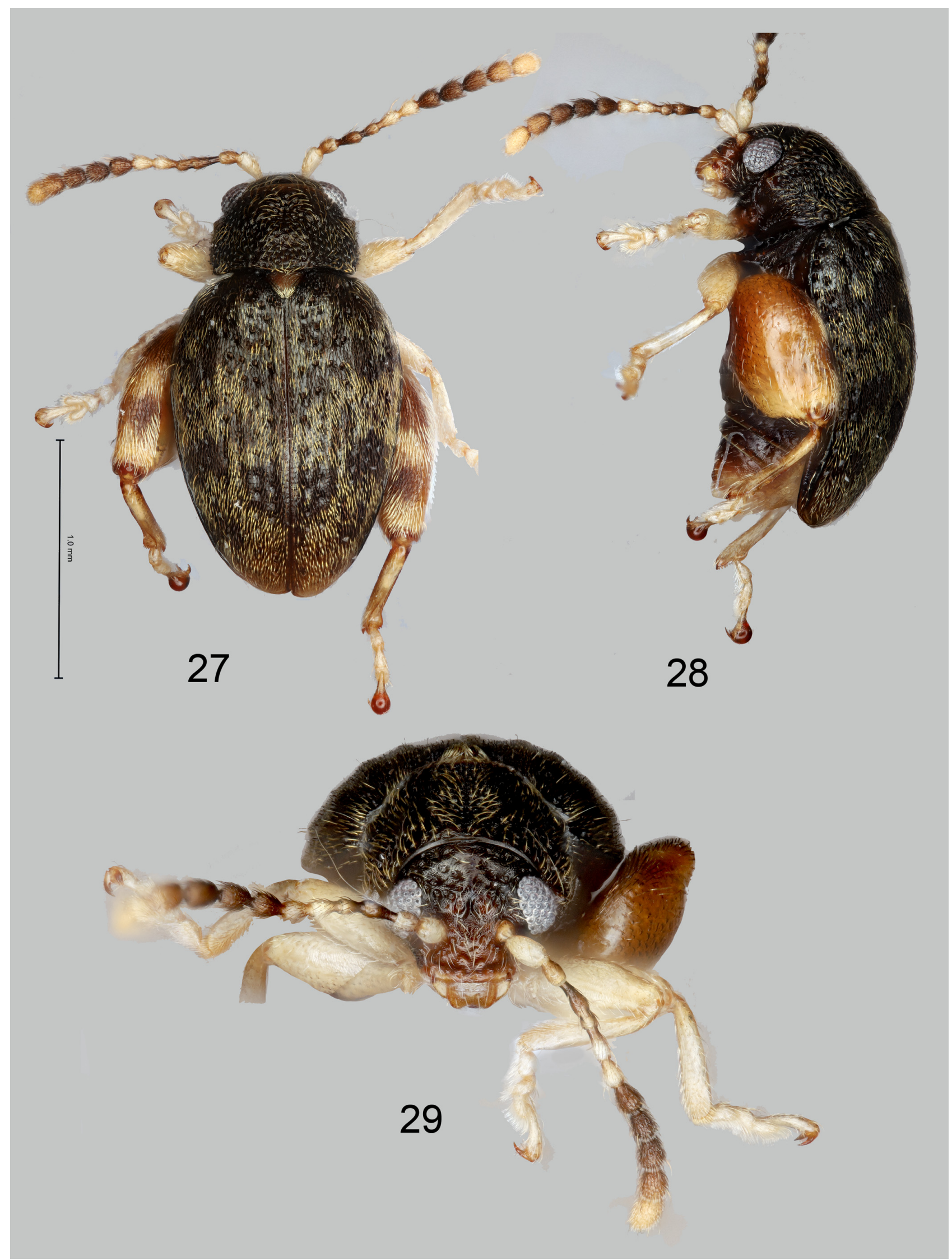

FIGURES 27-29. Menudos toronegro Linzmeier \& Konstantinov, new species, holotype. 27, habitus, male, dorsal view. 28, habitus, male, lateral view. 29, frontal view, male. 


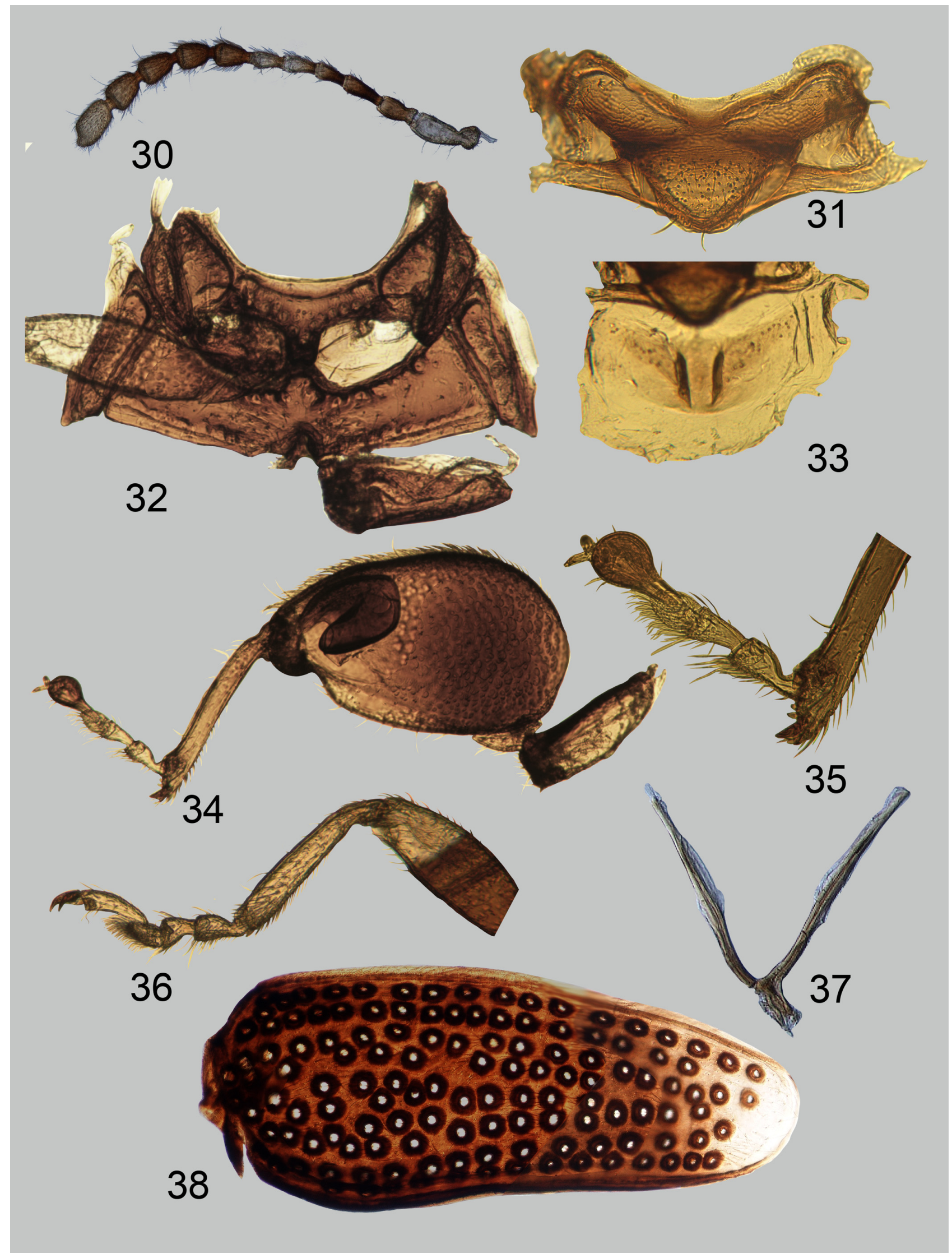

FIGURES 30-38. Menudos toronegro Linzmeier \& Konstantinov, new species. 30, antenna. 31, mesotergite. 32, meso- and metasternites. 33, metatergite. 34, hind leg. 35, hind tarsi. 36, middle leg. 37, metendosternite. 38, elytron. 


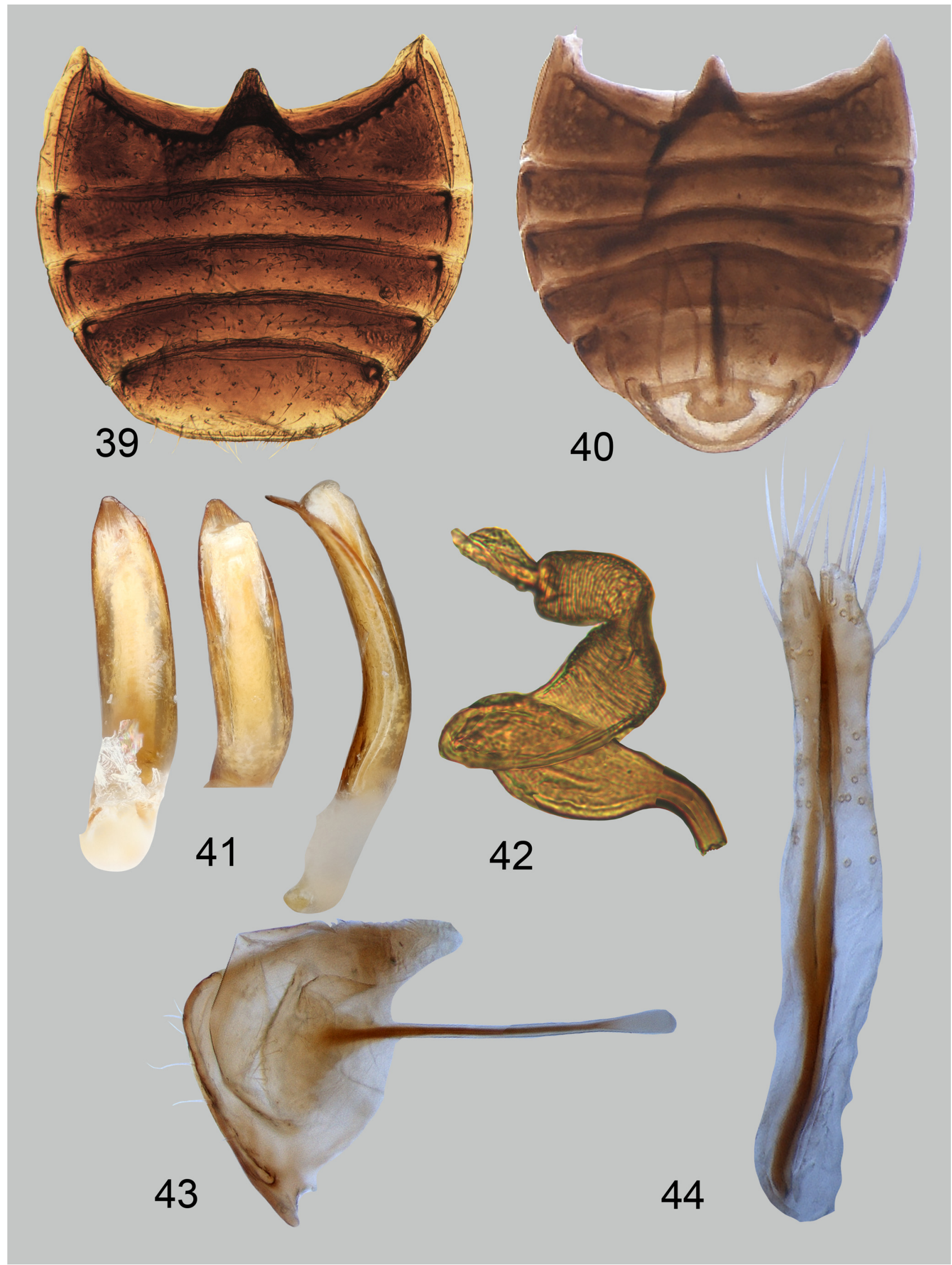

FIGURES 39-44. Menudos toronegro Linzmeier and Konstantinov, new species. 39, abdomen, female, ventral view. 40, abdomen, male, ventral view. 41, median lobe of aedeagus, holotype (ventral, dorsal, and lateral views). 42, spermatheca. 43, tignum. 44, vaginal palpi. 


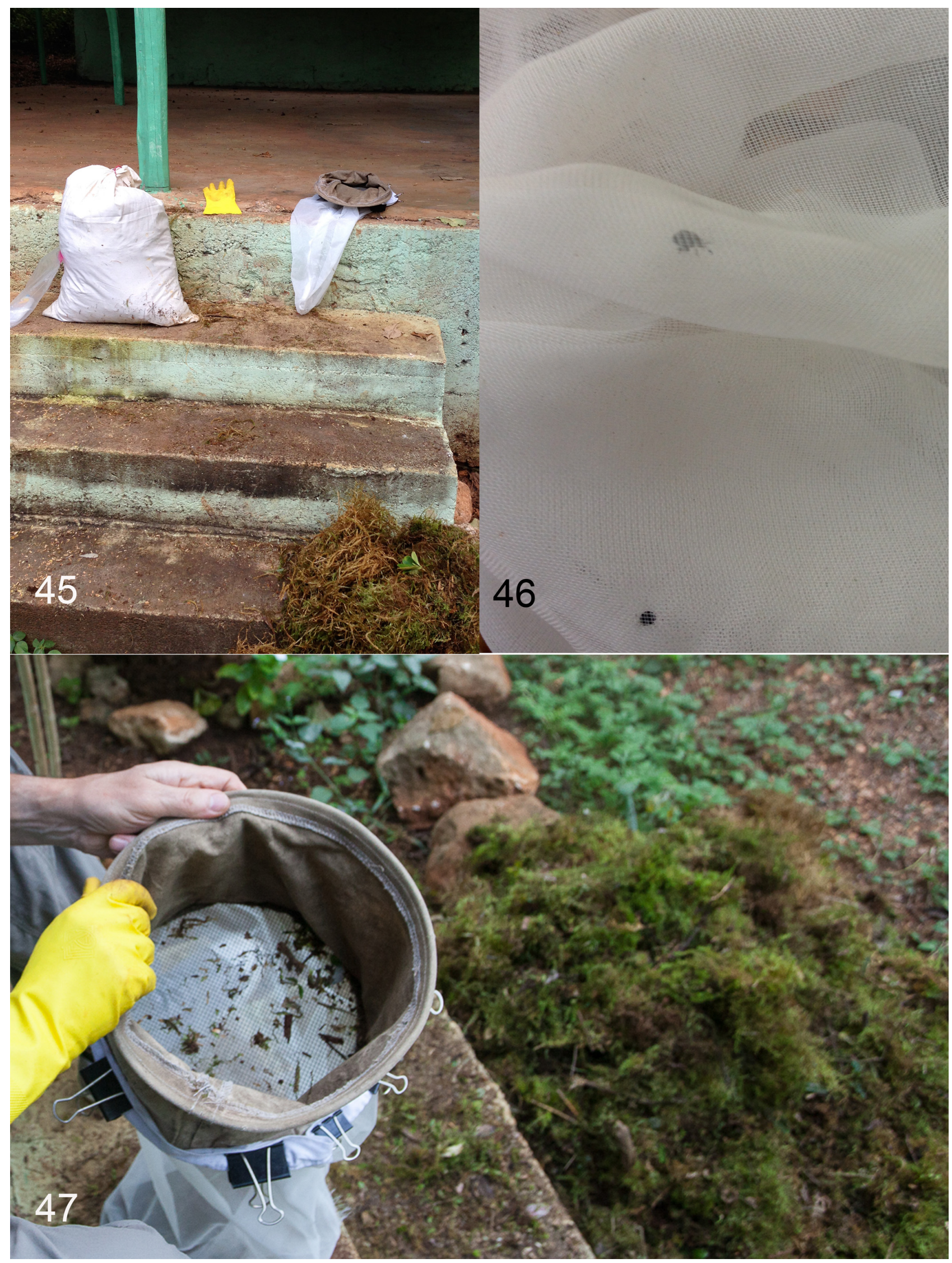

FIGURES 45-47. Methods for collecting moss inhabiting flea beetles. 45, bag of moss and sifter attached to a bag for sifting residue. 46 , flea beetle inside a bag for storing sifting residue. 47 , moss sifting in progress. 


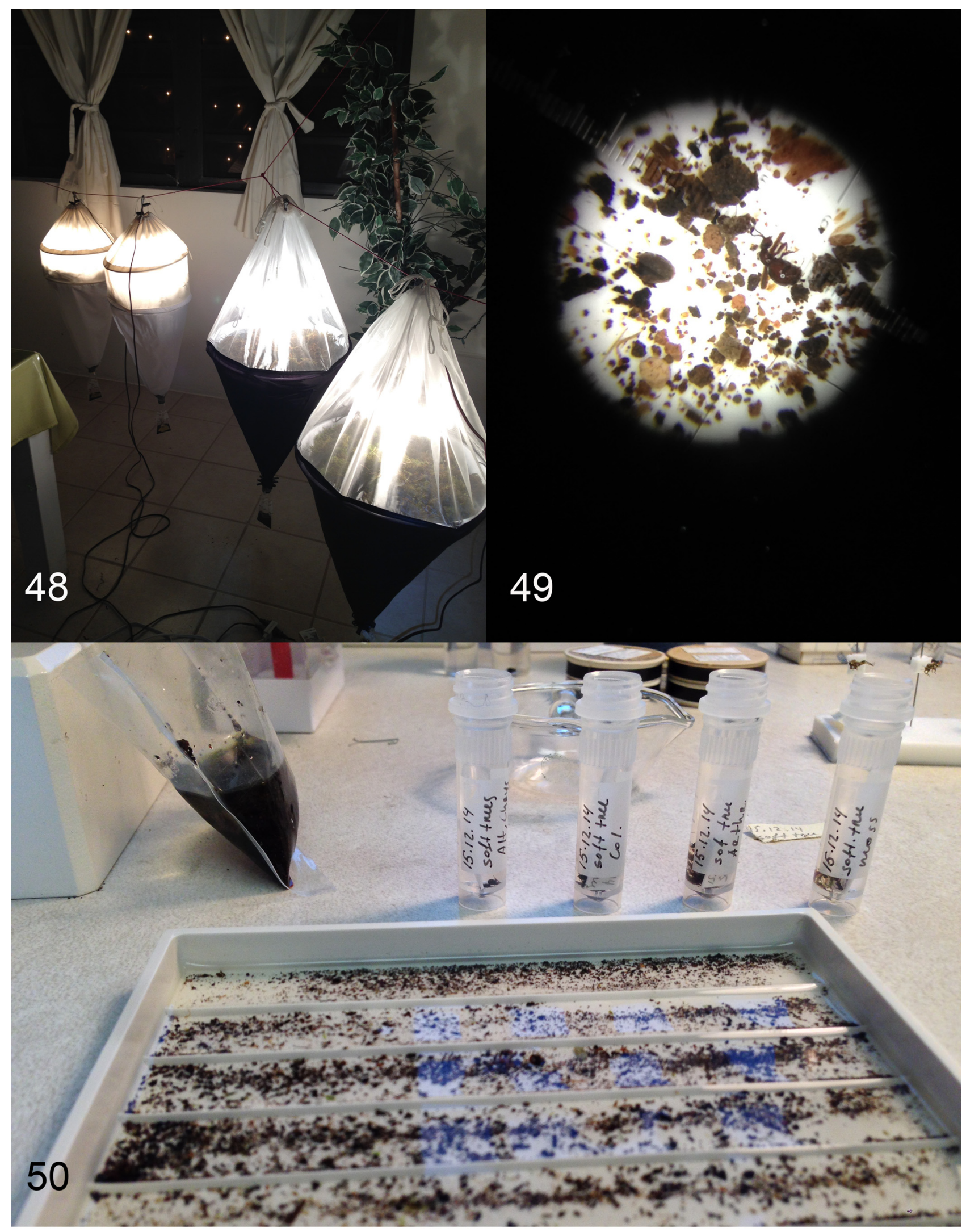

FIGURES 48-50. Methods for collecting moss inhabiting flea beetles. 48, Berlese funnels at work with attached whirls packs. 49 , sorting residue, view through microscope ocular. 50, tray for sorting moss sifting residue with vials for storing beetles and other arthropods. 
strongly and evenly sclerotized. Tignum generally straight with anterior end slightly narrower than posterior, rest of its surface moderately sclerotized. Vaginal palpi slender, fused anteriorly along one third of its length.

Diagnosis. Menudos toronegro can be easily differentiated from other species of Menudos by the following features: antennomeres 1 and 2, 5 and 6, and 10 and 11 whitish; antennomeres 3 and 4, 7-9 brown; golden yellow elytral pubescence arranged with 5 abruptly bent transverse bands (first - basal, band reaches suture); median lobe of aedeagus ventrally with lateral margins converging gradually towards apex, which forms barely distinct denticle.

Habitat. Menudos toronegro was collected on Toro Negro. Moss bearing tree was located about 10 meters away from side of the road that leads to the towers (Fig. 56).

Etymology. The specific epithet is a noun in apposition based on the type locality.

Type material. Holotype male, with labels as follows: 1) Puerto Rico: Toro Negro, 1.IX.2014/ N18.09.47 W66.31.20/ h-917m, WP-472 moss/ leg. A. Konstantinov; 2) Holotype Menudos toronegro des. A. M. Linzmeier \& A. Konstantinov, 2020 (USNM). Paratypes, with the same labels as holotype, 2 males, 1 female (USNM).

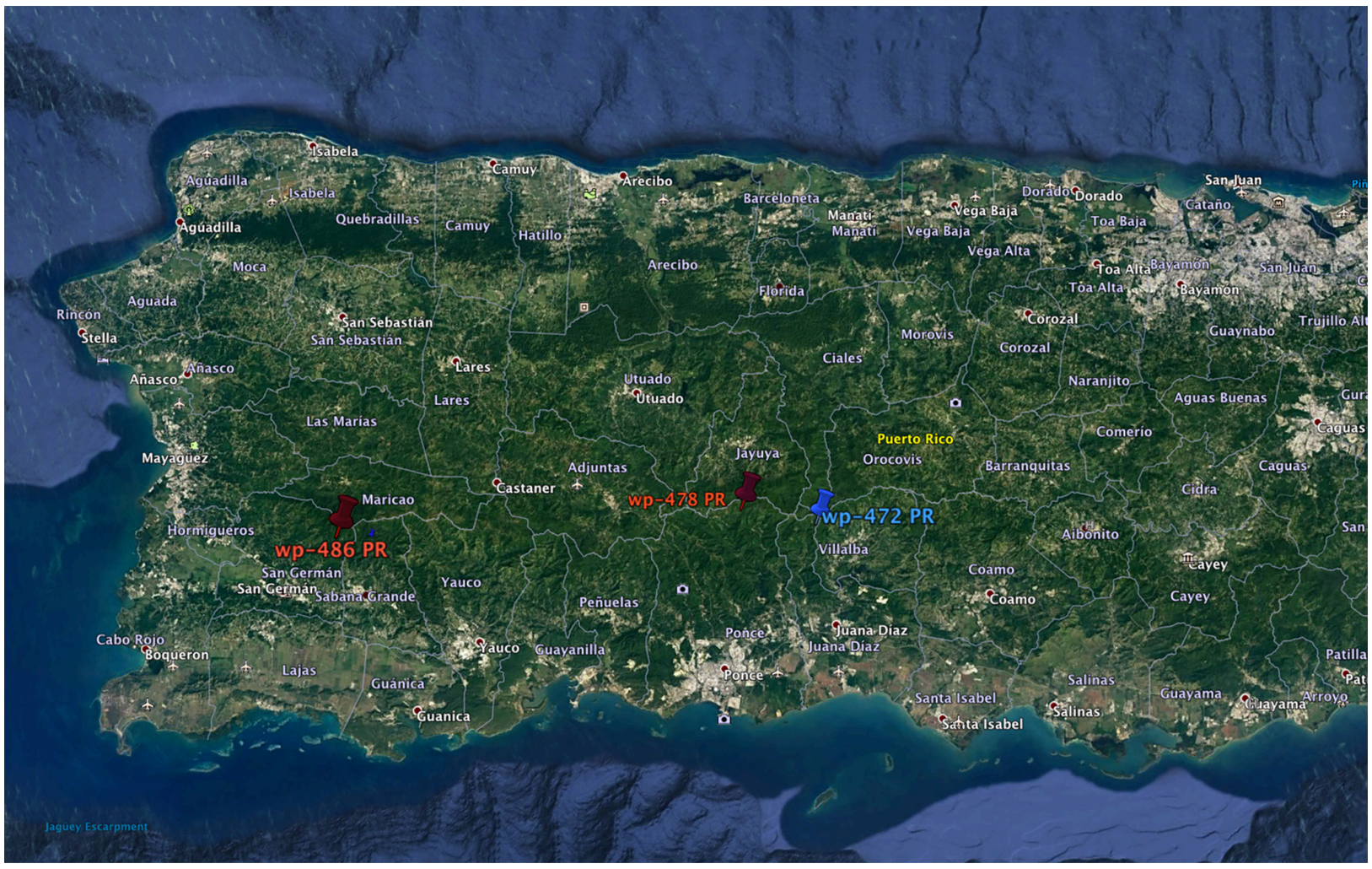

FIGURE 51. Map of Puerto Rico with moss collecting localities.

\section{Key to Menudos species}

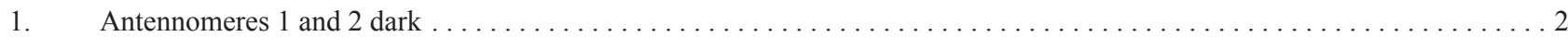

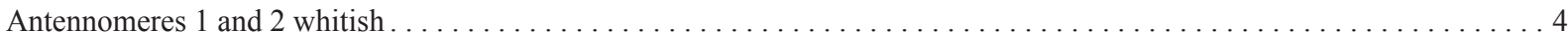

2 (1). Female elytron unicolorous, dark brown through its entire length, with setae forming at least three bent, transverse bands, not

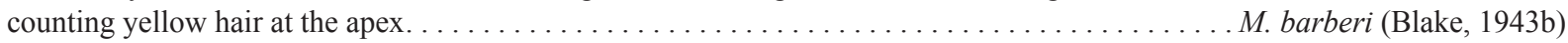
Female elytron bicolorous, black or dark brown at the base and yellow or light brown at the apex, with setae forming two bent,

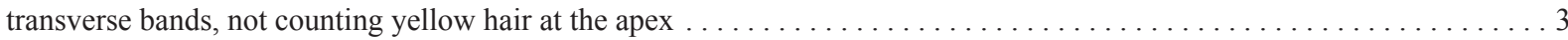

3 (2). Golden yellow setae do not form distinct pattern on elytra . . . . . . . . . . illariosus Linzmeier \& Konstantinov new species Golden yellow setae form distinct pattern on elytra............... chamorrae (Konstantinov \& Konstantinova, 2011)

4 (1). Antennomeres 1 and 2, 5 and 6, and 10 and 11 whitish. Antennomeres 3 and 4, 7-9 brown. Golden yellow elytral pubescence arranged with 5 abruptly bent transverse bands (first—-basal, band reaches suture). Punctures sparser on pronotal protuberances than between them. Median lobe of aedeagus ventrally with lateral margins converging gradually towards apex $\ldots \ldots \ldots \ldots$

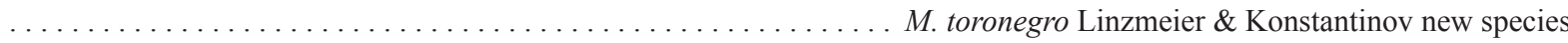
Antennomeres 1 to 6 and tip of antennomere 11 whitish. Antennomeres 7-10 brown. Golden yellow elytral pubescence arranged with 4 more or less straight transverse bands (first - basal, band the narrowest does not reach suture). Punctures as dense on pronotal protuberances than between them. Median lobe of aedeagus ventrally with lateral margins converging abruptly

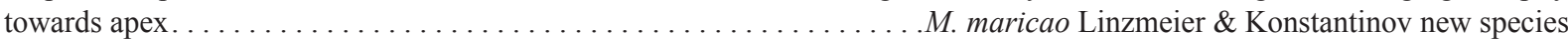




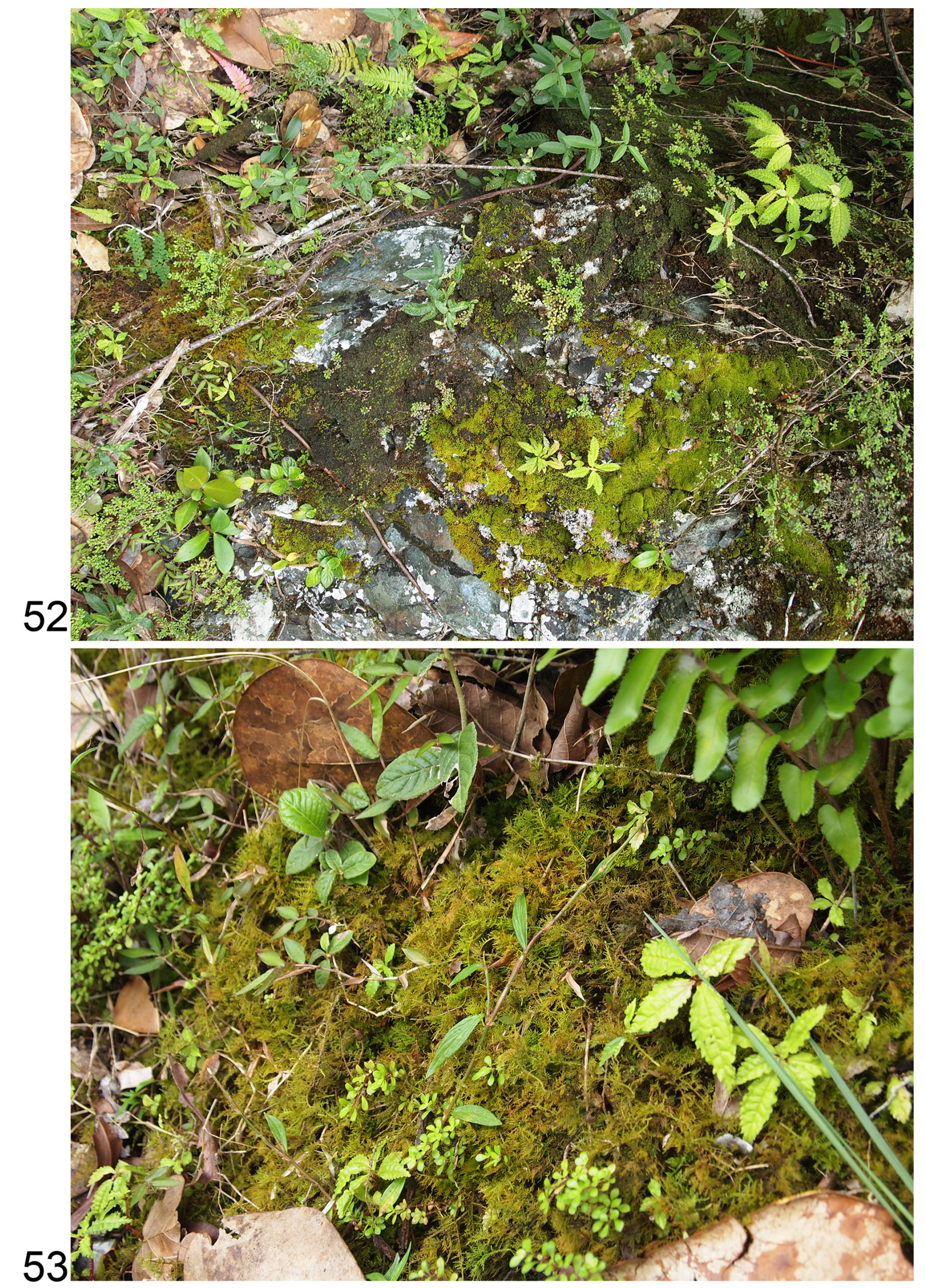

FIGURES 52-53. Moss in which flea beetles were collected near Maricao, WP-486. 

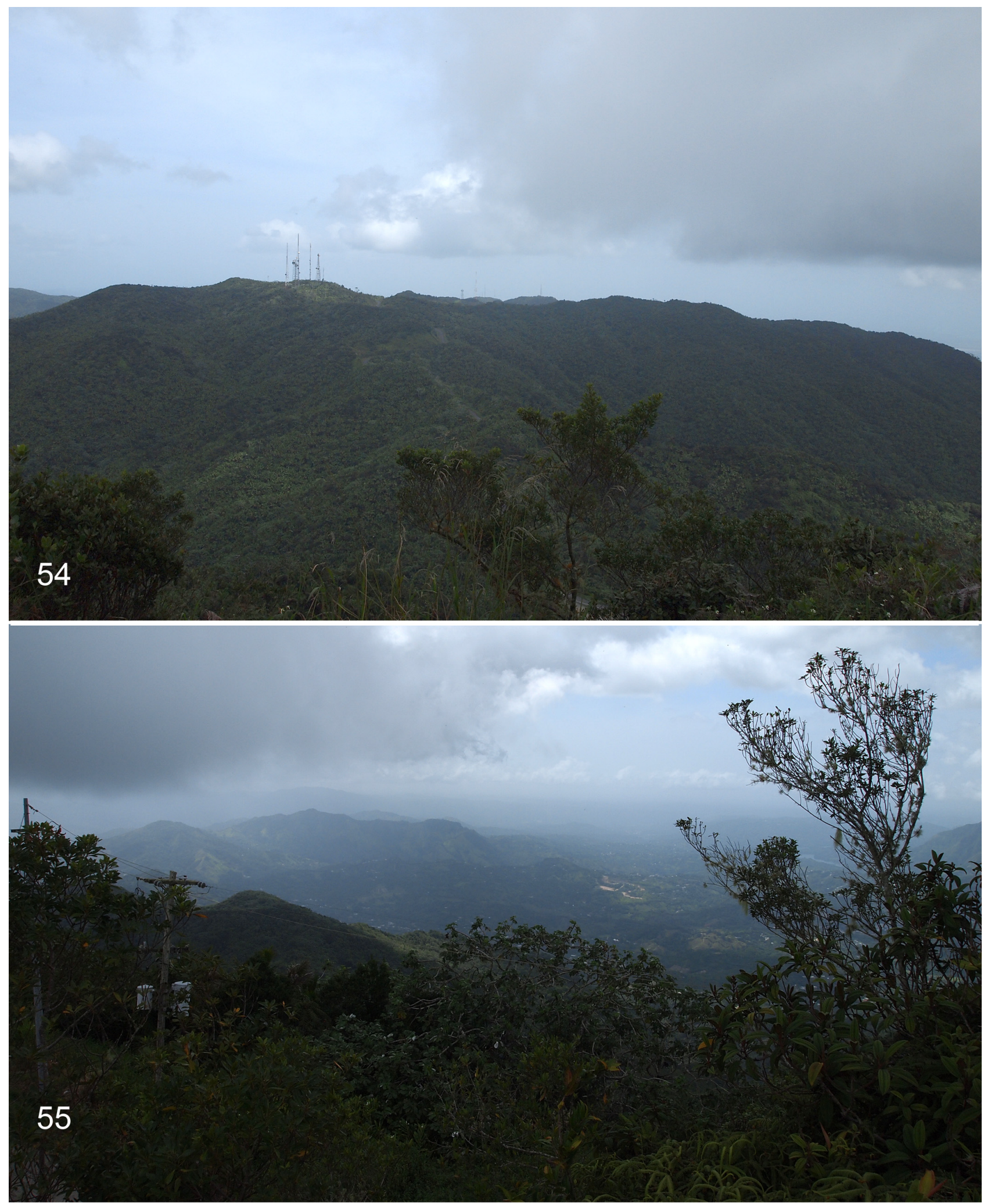

FIGURES 54-55. Landscape around Toro Negro. 54, view of the cell towers of Toro Negro from below. 55, view from the cell towers on the landscape below. 


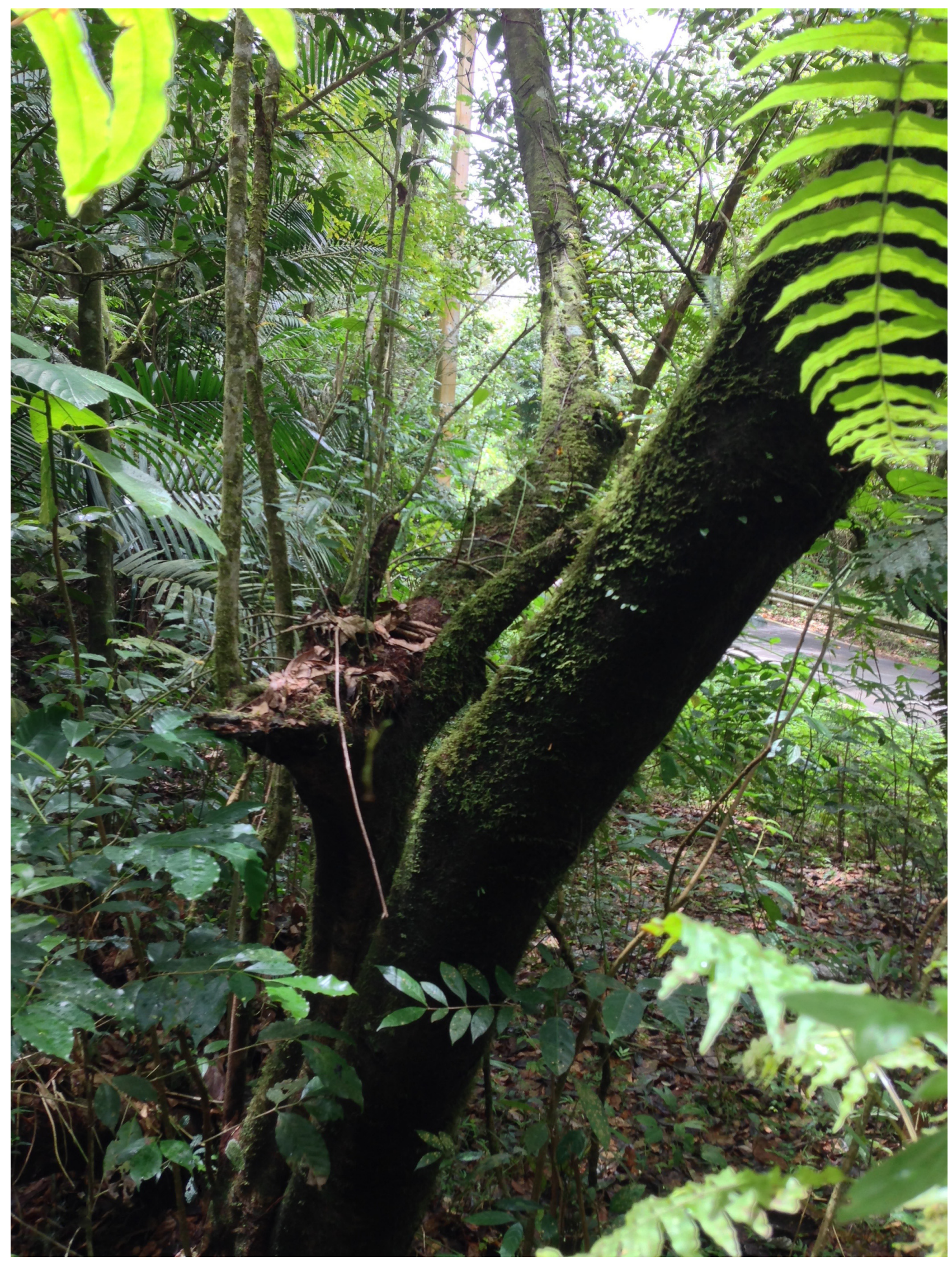

FIGURE 56. Moss bearing tree, habitat of Menudos toronegro. 


\section{Acknowledgements}

We thank Micheli family and Alex Segarra for hospitality and assistance with collecting permits while in Puerto Rico. Katie Sayers (Systematic Entomology Laboratory summer internship program, 2019) drew illustration of Menudos maricao. Jana Maravi (National Museum of Natural History internship program, 2015) took digital images of some specimens described here.

Shawn Clark and Michael Ivie shared with us their observation that Aedmon barberi is congeneric with Distigmoptera chamorrae, which we greatly appreciate.

Mention of trade names or commercial products in this publication is solely for the purpose of providing specific information and does not imply recommendation or endorsement by the USDA; the USDA is an equal opportunity provider and employer.

\section{References}

Bechyné, J. (1956) Über die Alticiden-Sammlung Heikertinger (Col. Phytophaga). Entomologische Arbeiten aus dem Museum G. Frey, 7, 577-598.

Blake, D.H. (1943a) The generic position of Hypolampsis pilosa (Illiger) and some related new species (Coleoptera: Halticinae). Proceedings of the Entomological Society of Washington, 45 (9), 207-221.

Blake, D.H. (1943b) New species of Hadropoda Suffrian from the West Indies. Bulletin of the Museum of Comparative Zoology, 92 (8), 413-441.

Clark, H. (1860) Catalogue of Halticinae in the collection of the British Museum. Part 1. Order ofTrustees, London, 301pp.

Konstantinov, A.S. (1998) Revision of the Palearctic species of Aphthona Chevrolat and cladistic classification of the Aphthonini (Coleoptera: Chrysomelidae: Alticinae). Memoirs on Entomology, International, Associated Publishers, Gainesville, $429 \mathrm{pp}$.

Konstantinov, A.S. \& Chamorro-Lacayo, M.L. (2006) A new genus of moss-inhabiting flea beetles (Coleoptera: Chrysomelidae) from the Dominican Republic. The Coleopterists Bulletin, 60 (4), 275-290. https://doi.org/10.1649/0010-065X(2006)60[275:ANGOMF]2.0.CO;2

Konstantinov, A.S., Chamorro, M.L., Prathapan, K.D., Ge, Si-Qin \& Yang, X.-K. (2013) Moss-inhabiting flea beetles (Coleoptera: Chrysomelidae: Galerucinae: Alticini) with description of a new genus from Cangshan, China. Journal of Natural History, 47 (37-38), 2459-2477. https://doi.org/10.1080/00222933.2012.763068

Konstantinov, A.S. \& Konstantinova, A.A. (2011) New genus and species of flea beetles (Coleoptera, Chrysomelidae, Galerucinae, Alticini) from Puerto Rico, with comments on flea beetle diversity in the West Indies and a key to the West Indian Monoplatini genera. ZooKeys, 155, 61-87. https://doi.org/10.3897/zookeys. 155.2124

Konstantinov, A.S., Linzmeier, A.M., Morais, A.C.C, Palmer, M.W., Scheffer, S.J. \& Lewis, M.L. (2019) Discovery of the first neartic moss-eating flea beetle, Distigmoptera borealis Blake, 1943 (Coleoptera: Chrysomelidae: Galerucinae: Alticini). The Coleopterists Bulletin, 73 (3), 599-610. https://doi.org/10.1649/0010-065X-73.3.599

Konstantinov, A.S., Linzmeier, A.M., Scheffer, S.J. \& Lewis, M.L. (2020) Moss-inhabiting flea beetles of the West Indies I: New species of Borinken Konstantinov and Konstantinova and Kiskeya Konstantinov and Chamorro-Lacayo (Coleoptera: Chrysomelidae: Galerucinae: Alticini) from Puerto Rico. Insecta Mundi. [in press]

Lawrence, J.F. \& Slipinski, A. (2013) Australian beetles. Morphology, Classification and Keys. Vol. 1. CSIRO Publishing, Collingwood, $561 \mathrm{pp}$. https://doi.org/10.1071/9780643097292

Lingafelter, S.W. \& Konstantinov, A.S. (2000) The monophyly and relative rank of alticine and galerucine leaf beetles: A cladistic analysis using adult morphological characters (Coleoptera: Chrysomelidae). Entomologica Scandinavica, 30 (4), 397-416. https://doi.org/10.1163/187631200X00525

Linzmeier, A.M. \& Konstantinov, A.S. (2012) A new genus of leaf litter inhabiting Neotropical Monoplatina (Coleoptera: Chrysomelidae: Galerucinae: Alticini). Zootaxa, 3260 (1), 19-32. https://doi.org/10.11646/zootaxa.3260.1.2

McHugh, J.V., Marshall, C.J. \& Fawcett, F.L. (1997) A study of adult morphology in Megalodacne heros (Say) (Coleoptera: Erotylidae). Transactions of the American Entomological Society, 123 (4), 167-223.

Scherer, G. (1962) Bestimmungsschlüssel der neotropischen Alticinen-Genera (Coleoptera: Chrysomelidae: Alticinae). Entomologische Arbeiten aus dem Museum G. Frey, Tutzing, 13, 497-606. 